\title{
End Use Analysis: Issues and Lessons
}

\author{
Stuart White, Geoff Milne and Chris Riedy \\ INSTITUTE FOR SUSTAINABLE FUTURES \\ University of Technology, Sydney \\ P.O. Box 123, BROADWAY NSW \\ SYDNEY AUSTRALIA
}

\begin{abstract}
Methodologies for end use analysis have been developed by different researchers in the energy and water fields and in different areas in the world over the last 20 years. While there are core features associated with the methodologies and models used, the differences can provide insight into the ways that they might be improved, as well as the differences that may be required in different regions and when models are used for different purposes.

In addition to reviewing the field of end use analysis and appliance stock models, this paper will focus on two case studies. The first is the Sydney Water End Use Model, developed as part of the Sydney Water Least Cost Planning Study. This model has been developed and used to project the demand for water in Sydney over the next 20 years under business as usual scenario, as well as allow the projection of a number of scenarios which include major investment in water efficiency and effluent reuse programs as well as regulatory options to improve the efficiency of water using appliances in stalled in new buildings.
\end{abstract}

Key features of the Sydney Water End Use Model include the fact that it takes into account the fact that the efficiency of toilets in Australia has a much larger range than (say) the US, in that the dual flush toilet was introduced in (to date) three stages. The model also accounts for projections of demographic and land use change which has been particularly dramatic in Sydney, particularly the movement to smaller occupancy rates in dwellings, and towards multi-family residential dwellings.

The second case study will demonstrate the linkages between end use modeling of energy using and water using appliances. A model of residential energy use in Australia has been developed as part of a research project to develop greenhouse abatement scenarios for Australia, and many of the appliances modeled overlap with the water end use model, including clothes washing machines, dishwashers, showerheads and taps. This more recent modeling exercise has revealed the importance of key assumptions in standard stock modeling techniques, and highlighted the need for earlier starting dates for stock modeling.

The process and results of these two case studies will be presented, and conclusions drawn about further improvements in end use analysis for both water and energy use. The linkage between the use of backcasting as a planning tool, and the use of end use analysis as a pre-requisite for the development of a demand management program is highlighted.

Keywords: Water efficiency, urban water demand, end use analysis, demand modeling, backcasting 


\section{Introduction}

End use analysis is one of a number of techniques that can assist water utilities to understand the demand for water, to enable projections of water demand and to design effective demand management programs. It involves disaggregating demand into the 'services' people actually use water to provide and hence is based on the perspective is of providing a service (eg cleaning clothes), rather than a commodity (water). This is an important principle of integrated resource planning (Howe and White 1999).

Traditionally demand forecasting was undertaken on the basis of historic trends of per capita consumption or multiple regression techniques using a range of variables such as population, income, price of water and periods of restrictions. However, what was important in the past may not be in the future, and these approaches often result in oversupply. Figure 1 (from White 1996) shows the different forecasts of demand that would be obtained by extrapolating trends of per capita demand from different periods for Sydney, Australia.

Figure 1 Results obtained from extrapolation of per capita demand using different periods.

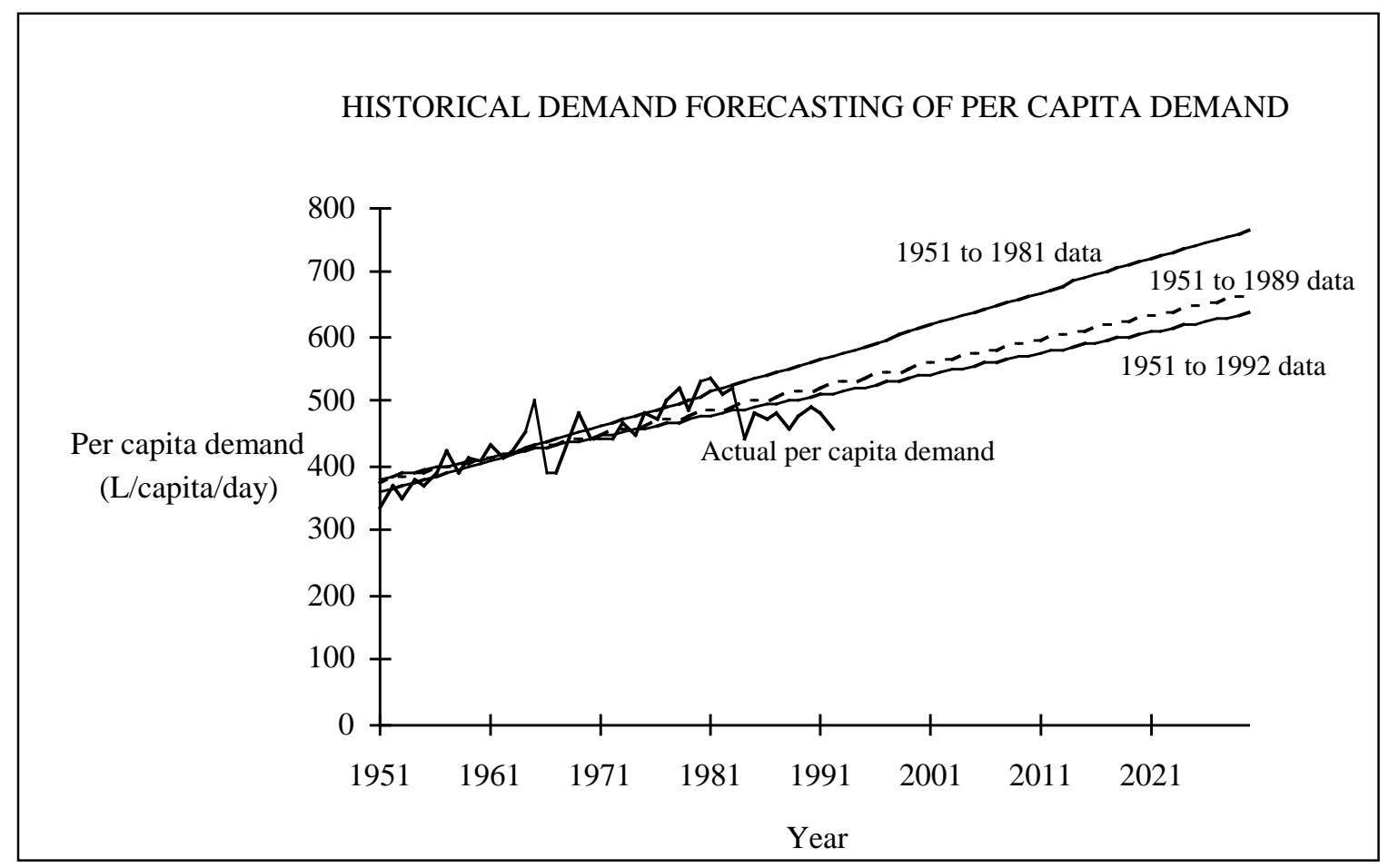

Multiple regression models establish a relationship between demand per capita or per connection and variables that include weather related variables, changes in pricing structure, major changes in industrial demand, the imposition of water restrictions and other factors which influence demand. Such models are useful for assessing historical demand, and for providing a baseline to compare demand after implementation of a demand management program, but are limited in their ability to project demand into the future due to the aggregated nature of the variables.

The advantages of a disaggregated modeling process which includes end uses is that it can be used to model potential demand management programs, rather than merely as a means of understanding the current demand. This distinction, between modeling processes that are designed to understand current demands and to extrapolate them based on current trends and modeling processes that are explicitly designed to support change strategies, is summarized in the difference between forecasting and backcasting (Rotmans, et al., 2000). Forecasting is the traditional and dominant approach to scenario development and futures studies. It is a method used to develop scenarios by making forward projections of selected system variables such as population, gross domestic product (GDP) or energy consumption. 
Forecasting is concerned with existing trends and is generally used to generate "business-as-usual" (BAU) scenarios that pre-suppose continuation of the existing trends and paradigm into the future.

As forecasting methods are based on dominant trends, they tend to describe futures that look much like the present and they are of little use in generating solutions that presuppose the breaking of trends (Dreborg, 1996). Their value as a predictive tool also diminishes rapidly as the timescale under consideration increases, due to the inability of the method to anticipate surprises and discontinuities.

The limitations of forecasting have encouraged the development of alternative and complementary approaches, such as backcasting, to assist in the development of more complete sets of future scenarios. Backcasting is a method developed to explore the means by which specified future states can be attained. As the name suggests, it is essentially the opposite of forecasting. Whereas forecasting works forward, from the present to the future, backcasting works back from the future to the present. Backcasting is concerned:

not with what futures are likely to happen, but with how desirable futures can be attained. It...(involves) working backwards from a particular desired future end-point to the present in order to determine the physical feasibility of that future and what policy measures would be required to reach that point (Robinson, 1990, p. 822-823).

One of the first applications of backcasting was in the energy field (Lovins 1977). The case studies discussed in the following section, the Sydney Water End Use Model and an Australian residential energy use model, are explicit examples of the backcasting principle.

\section{End Use Analysis: Case Studies}

This section describes two case studies that illustrate the application of end use analysis within the framework of backcasting.

\subsection{The Sydney Water End Use Model}

The Sydney Water End Use Model was developed as part of the Sydney Water Least Cost Planning Study. This study had the objective of determining the least cost means of reducing the demand for water from Sydney Water storages, in order to meet operating licence conditions that include a requirement to reduce demand for water by 35\% in per capita terms between 1991 and 2011. Demand in 1991 was 503 litres per capita per day, and is currently (2002) approximately 430 litres per capita per day. Further details of this program and its context can be found in Howe and White (1999) and at the websites of Sydney Water Corporation ${ }^{1}$ and the licence regulator (the NSW Independent Pricing and Regulatory Tribunal ${ }^{2}$ ).

The Sydney Water End Use Model was based on the development of a time series 'stock' model for each end use.

There are different approaches to this dependent on the particular end use:

- a vintage stock model where technical efficiency varies over time (eg dishwashers and clothes washers) as it is important to know, for example, how many appliances sold 10 years ago are still in use.

- an ownership stock model where technical efficiency is constant over time and it is only necessary to model ownership levels. For example water efficient shower heads ${ }^{3}$ sold 10 years ago will have the same flow rate as one sold yesterday, so we only need to know the number in use at present.

The stock model does not tell us directly the water consumption of the end use, it is just the 'stock' part of the equation - usage and technical parameters are required for that. The vintage stock model used for this analysis was developed at the Environmental Change Unit at the University of Oxford as part of the DECADE modeling process for energy demand analysis (ECI 2000).

The initial step of the end use analysis process is to disaggregate water demand to the maximum extent possible, including sector breakdown (single family residential, multi-family residential, commercial, 
industrial, institutional and unaccounted for water), broad categories within these sectors if possible (eg indoor and outdoor use) as shown in Figure 2, and ultimately specific end uses where data are available (eg toilet flushing, showers and so on). In the case of the demand for water in Sydney, the largest single component is indoor residential water use. This is fortunate, given that this is the one sector where the end use modeling process has the least uncertainty associated with it.

Figure 2 Water consumption by sector in 1997 for Sydney Water.

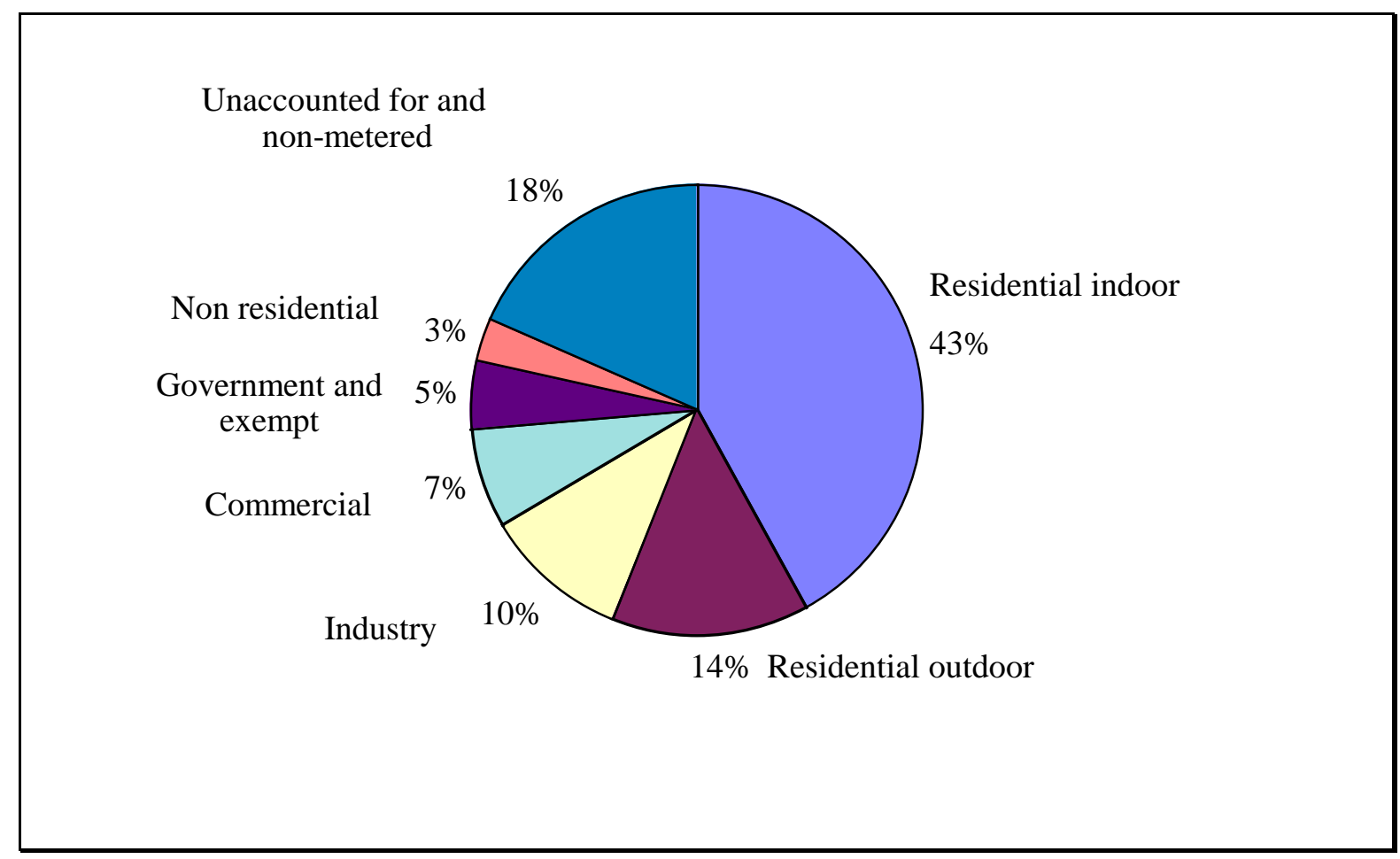

The end use methodology requires incorporating all available data in relation to appliance stocks, turnover, efficiency levels, usage patterns, occupancy rates, population and building types.

The residential end use model considers household water usage in categories and sub-categories. Estimates of the water consumption for each of these uses are then made based on parameters such as:

- ownership patterns;

- technical characteristics of water using appliances;

- surveys of water using behaviour;

- occupancy; and

- housing type. 
A general outline of the modeling process is shown in Figure 3.

Figure 3 Outline of the residential end-use model.

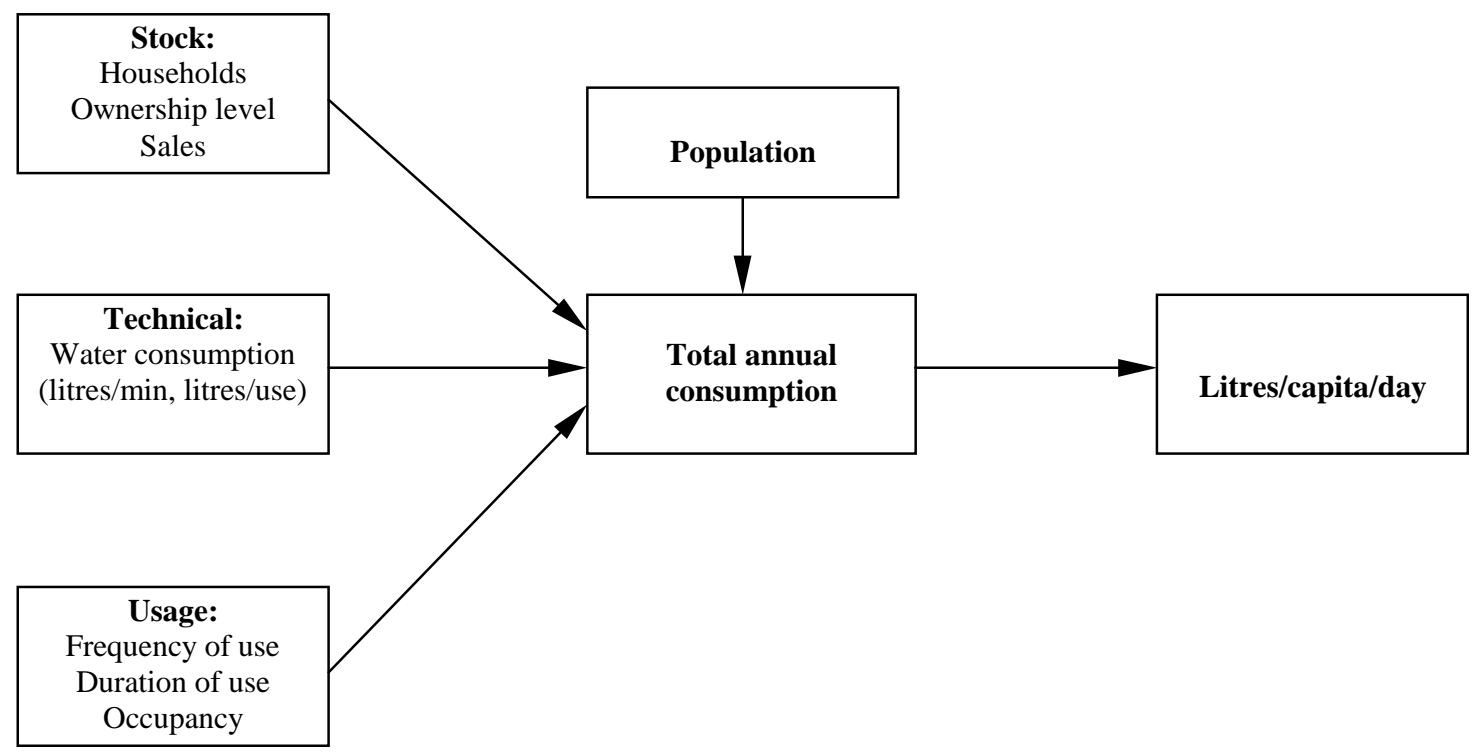

The major categories of residential end uses considered for Sydney are as shown in Table 1.

Table 1 The components of the residential end-use model for Sydney.

\begin{tabular}{|c|c|c|}
\hline \multirow[t]{9}{*}{ Indoor } & \multirow[t]{3}{*}{ Bathroom } & Shower \\
\hline & & Bath \\
\hline & & Basin taps \\
\hline & Toilet & Cistern \\
\hline & \multirow[t]{3}{*}{ Kitchen } & Dishwashing machine \\
\hline & & Sink taps \\
\hline & & Insinkerator \\
\hline & \multirow[t]{2}{*}{ Laundry } & Clothes washing machine \\
\hline & & Trough \\
\hline \multirow[t]{6}{*}{ Outdoor } & \multirow[t]{2}{*}{ Watering } & Gardens \\
\hline & & Lawns \\
\hline & \multirow[t]{2}{*}{ Car washing } & Bucket \\
\hline & & Hose \\
\hline & Hosing down & \\
\hline & Swimming pools & \\
\hline
\end{tabular}

Other regions will have different end uses. For example, recent work in Alice Springs, in Australia's arid zone, indicates that evaporative air-conditioners will be a significant end use (Turner et al. 2003).

Figure 4 shows the results of an ownership stock model for toilet suites for Sydney, Australia (ISF 1999). These results, which show the stock of three types of dual flush toilet and also a single flush toilet, contrast with other countries where there are essentially two types of toilet, standard and ultra-low flush. This illustrates the importance of tailoring the model to suit the local conditions. 


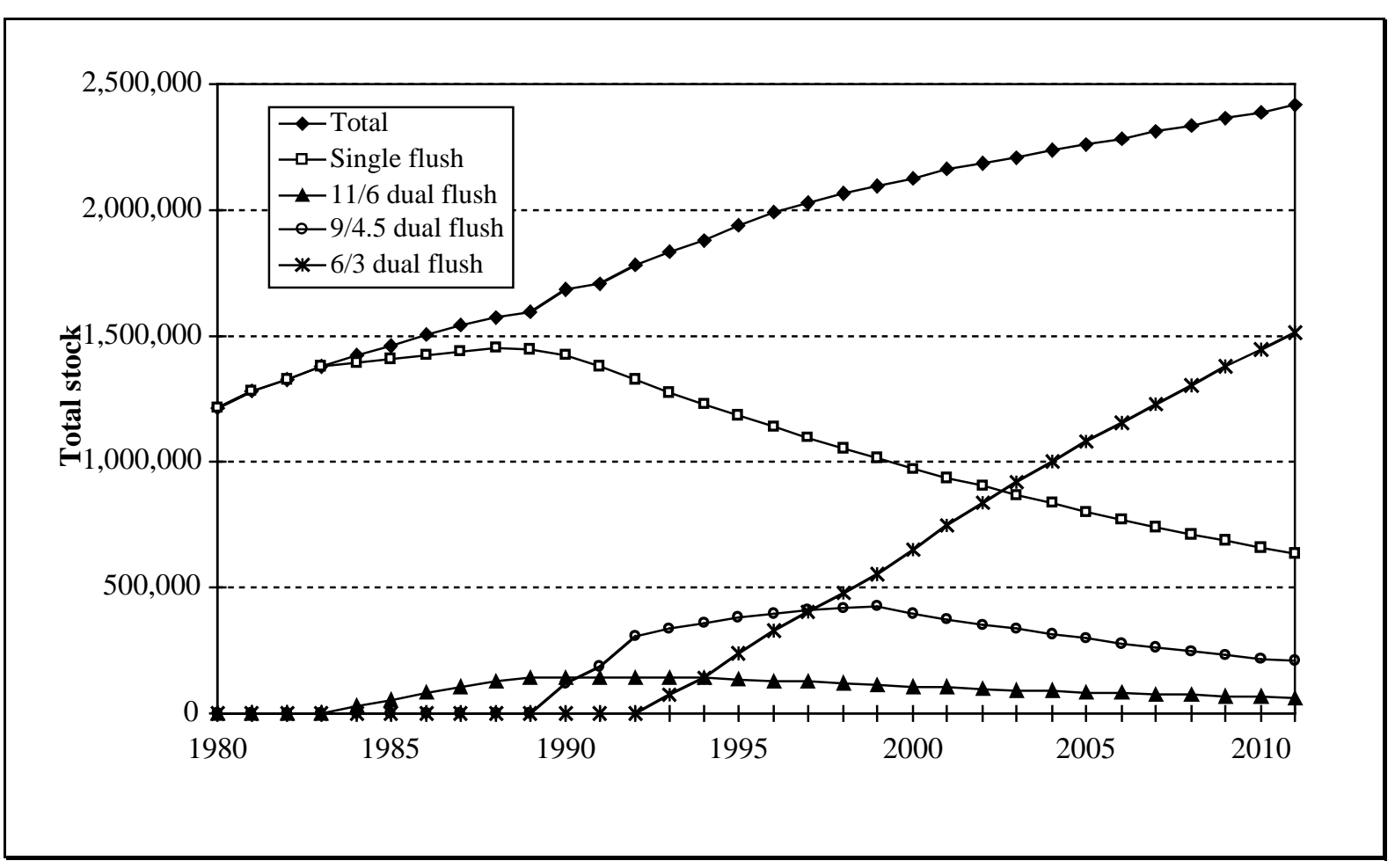

The demand for water in Sydney is lower than many other cities. Table 2 shows a comparison with results from end use analysis in Bangkok and the East Bay area of San Francisco (East Bay Municipal Utility District - EBMUD). The Bangkok and EBMUD data are from Darmody, Maddaus and Beatty (1998:286).

Table 2

Results of end use analysis for residential indoor water use for three cities including Sydney, Australia.

\begin{tabular}{|l|c|c|c|}
\hline \multicolumn{1}{|c|}{ Parameter } & Bangkok & EBMUD & Sydney \\
\hline Total per capita production (litres per person per day) & 588 & 591 & 430 \\
\hline $\begin{array}{l}\text { Internal residential per capita demand (litres per } \\
\text { capita per day) }\end{array}$ & & & \\
\hline Toilet & 27 & 63 & 45 \\
\hline Dishwasher & 4 & 10 & 2 \\
\hline Shower & 66 & 44 & 57 \\
\hline Faucets & 25 & 39 & 19 \\
\hline Laundry & 45 & 63 & 49 \\
\hline Baths & 2 & 15 & 9 \\
\hline Leakage & 21 & 10 & 3 \\
\hline
\end{tabular}

\subsection{An Australian Residential Energy Use Model}

An Australian residential energy use model has been developed as part of a wider research project exploring long-term energy and greenhouse futures for Australia. The research project uses backcasting to establish a target to reduce Australia's energy-related greenhouse gas emissions by $50 \%$ by 2030 , 
relative to 2000 emissions. Multiple criteria analysis and targeted modeling are then used to identify the most attractive greenhouse abatement options for the Australian stationary energy sector, consistent with this long-term greenhouse abatement target.

The residential energy use model is an end use model used to assess possible impacts of greenhouse abatement options in the residential sector, such as programs to improve appliance efficiency or encourage the use of fuels with lower greenhouse intensity. The model is a vintage stock model, based on the model developed by the Environmental Change Unit at the University of Oxford as part of the Lower Carbon Futures project. It builds on the energy demand analysis model developed for the DECADE project, and is documented in Appendix O of the Lower Carbon Futures 2000 Report (ECI, 2000).

The model covers all residential appliances that consume energy. As some of these appliances also use water (e.g. clothes washers, dishwashers and water heaters), there is overlap between the energy end use model and water end use models. Furthermore, as the basic procedure for energy end use analysis is much the same as that described for water, conclusions from stock modeling of energy using appliances are readily transferable to stock modeling of water using appliances.

The modeling process for energy is similar to that outlined in Figure 3 for the Sydney Water end use model, with the substitution of technical data on energy consumption (kilowatt hours per day, or per use) for technical data on water consumption. The average Australian household consumes about 6,800 kilowatt hours of electricity each year, and about 31 gigajoules of other fuels each year (not including energy used for transport). Table 3 gives the results of preliminary end use modeling for Australian residential energy use.

Table 3 Preliminary results of end use analysis for Australian residential energy use in 2000.

\begin{tabular}{|c|c|c|}
\hline \multirow{2}{*}{ Energy Service } & Appliance & $\begin{array}{c}\text { Proportion of Total Annual } \\
\text { Household Energy Use (\%) }\end{array}$ \\
\hline \multirow{2}{*}{ Cold storage } & Refrigerator & 7 \\
\hline \multirow{2}{*}{ Laundry services } & Freezer & 2 \\
\cline { 2 - 3 } & Clothes washer & 4 \\
\hline Space conditioning & Clothes dryer & 36 \\
\hline Hot water & Heaters, air conditioners & 27 \\
\hline Lighting & Water heater & 4 \\
\hline Food preparation & Light fittings & 4 \\
\hline Entertainment & Ovens, cooktops, microwave & 1 \\
\cline { 2 - 3 } & Dishwasher & 1 \\
\hline Miscellaneous & Television & 12 \\
\cline { 2 - 3 } & Small appliances, standby power & Video \\
\hline
\end{tabular}

Water using appliances accounted for 32 per cent of total residential energy consumption in Australia in 2000, which demonstrates the importance of considering interactions and possible synergies between energy and water efficiency programs.

Figure 5 shows one of the outputs from a vintage stock model, using clothes washers as an example. The figure shows the vintage of the total stock present in any given year, and demonstrates how long it takes for an appliance to make its way through the stock. 


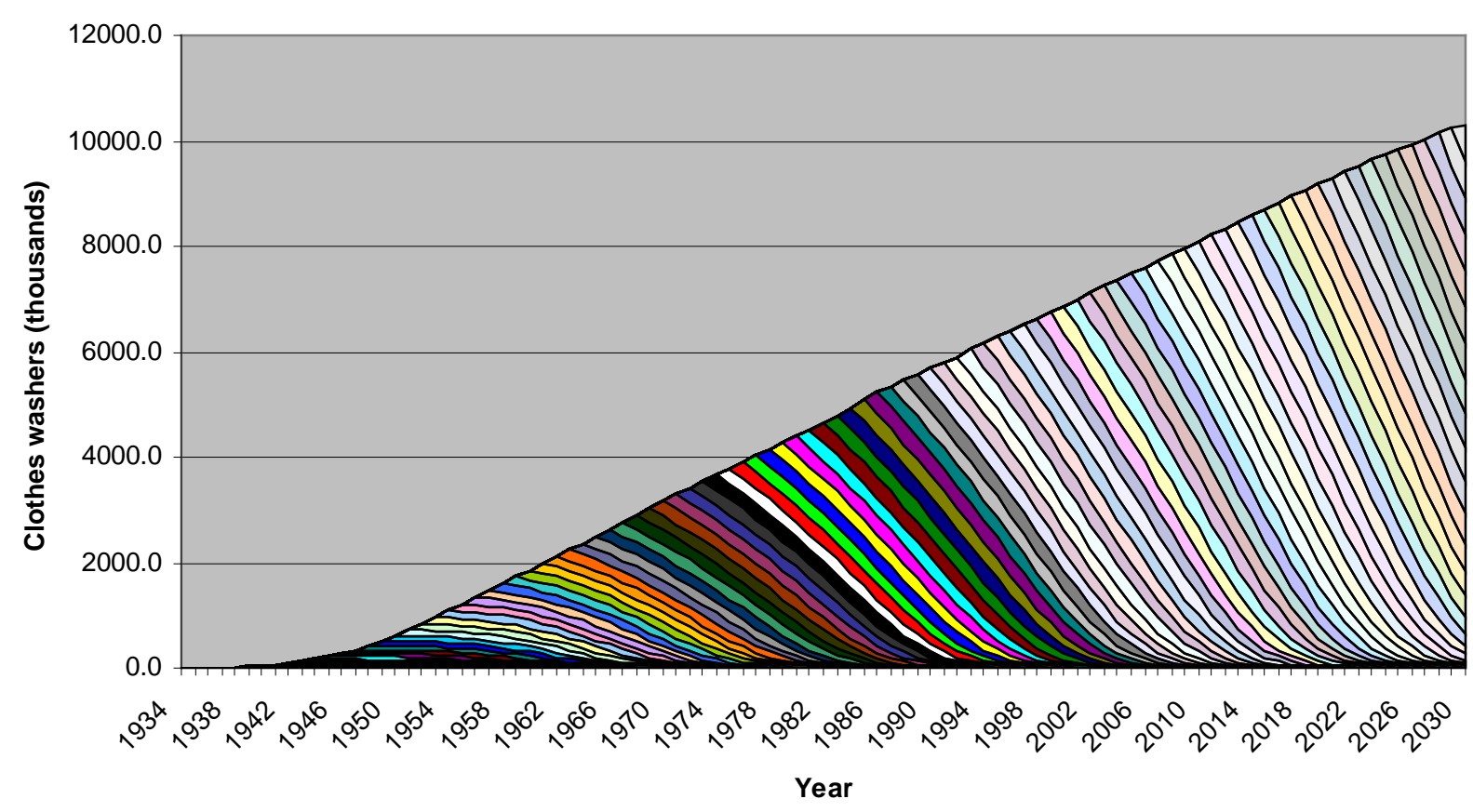

The residential energy end use model relies on estimates of appliance sales in each year. Annual sales need to be estimated due to the lack of continuous and reliable actual sales data for most appliances. Sales are estimated using the known (or assumed) appliance ownership in each year, sales in previous years and assumptions about the time taken for appliances to retire from the stock. Estimated sales in any given year are equal to the total stock of appliances (derived from ownership data) minus the sum of all appliances sold in previous years that still remain in the stock. The average service life of an appliance is needed to determine how long the appliance is likely to remain in the stock. Estimated sales are often calibrated against actual sales data by varying the assumed service life.

Annual sales estimates are sensitive to the start date used in the stock model. For some appliances, such as video cassette recorders and dishwashers, the introduction of the appliance occurred relatively recently and is well documented. In these cases, the start date is for modeling can usually be set to the actual date when sales of the appliance first commenced. For other appliances, such as refrigerators and clothes washers, the introduction of the appliance occurred early in the $20^{\text {th }}$ Century, and is poorly documented. In these cases, it is common practice to select a start year for the modeling that is well after the actual year of introduction of the appliance (e.g. 1960) and to assume that all existing stock was sold in that year.

This assumption that all stock present in the start year is new leads to inaccurate stock modeling, as the stock present in the start year persists longer in the model than it would in reality. The result is underestimation of appliance sales in the early years of the model, due to false persistence of the initial stock. This is followed in later years by overestimation of sales, as the model tries to compensate for the low initial sales. Estimated sales oscillate with a frequency related to the average service life of the appliance (Lane, 2002, personal communication).

Continuing with the example of clothes washers, the actual start date for sales in Australia is around 1934, based on a review of historical sources. If a start date of 1960 is assumed, estimated model sales in 2000 are about 5 per cent lower than they are if a start date of 1934 is used. Similar results have been observed for other appliances. If the model is being calibrated against actual sales data, modelers may attempt to compensate for the change in sales by altering the assumed service life of the appliance. In the case of clothes washers, a service life of 15 years provides the best fit to the available data when 1934 is used as the start date, while 16 years provides the best fit to the data when 1960 is used. Analysis of other appliances indicates that an assumed 1960 start date can raise or lower the assumed service life, depending on the actual start date and the sales oscillation frequency. 
Sufficient data is usually available to make an informed estimate of the likely start year for sales of a particular appliance. Growth of ownership from the start date can be approximated using growth curves, linear regression and survey data on actual ownership. This approach will result in a more accurate stock model than one based on a common assumed start date. In the residential energy end use model, the use of more accurate start dates has led to revision of the assumed service life for a number of appliances.

\section{Limitations}

The limitations in end use analysis primarily relate to the lack of available data. There are several areas where this is an issue:

- The outdoor water use sector is generally poorly characterized, as the water use in this sector is dominated by user behaviour rather than the technical efficiency of equipment. Changes in lawn an garden watering are often driven by land use changes, such as the tendency for new developments to have larger houses on smaller lots, and a trend towards urban consolidation, which increases the proportion of multi-family dwellings.

- The commercial, industrial and institutional sectors have greater heterogeneity than the residential sector and are therefore more difficult to characterize. The commercial sector in particular, is dependent on employment and economic activity, and the industrial sector to long terms structural changes in the economy of a city. In Sydney, there was a major (over 20\%) improvement in the water use intensity of industrial sector between 1985 and 1995, which has continued at a slower rate.

- Some appliances or fixtures, such as shower heads, have insufficient sales data available which can lead to uncertainties in the characterization of stocks of different appliances.

\section{Conclusions}

The best way to improve end use analysis is to obtain better information on where and how water is currently being used. The use of multiple data sources can help achieve this, for example, by complementing and supporting stock models with:

- Survey data that involves actual inspection rather than relying on householders to be able to identify 'water efficient showerheads' or distinguish between different types of dual flush toilets (see Cordell and Robinson 2003).

- Multiple regression models that allow an independent estimate of outdoor water use.

- Analysis of sector based demand data, on a seasonal basis.

- The use of data logging to determine actual water efficiency performance and frequency of use of appliances.

End use analysis which is being undertaken with the objective of reducing the demand for water represents an application of the principles of backcasting. This focuses the end use analysis and provides a framework for more robust results, which can be tested with the implementation of demand management programs. 


\section{References}

Cordell, D and Robinson, J (2003) 'Collecting residential end use data from primary sources: do's and don'ts' Proceedings of Efficient 2003, The Second International Water Association Conference on Water Efficiency, Tenerife, Spain, April.

Darmody, J, Maddaus, W, and Beatty, R (1998) 'Water use surveys improve the effectiveness of demand management', Proceedings of the $11^{\text {th }}$ IWSA-ASPAC Regional Conference, Integrating the Urban Water Cycle, Sydney, 1-5 November 1998.

Dreborg, K H (1996) 'Essence of Backcasting' Futures 28 (9) 813-828

ECI (2000) 'Lower carbon futures for European households', Oxford, Environmental Change Institute, Ecofys, ISR, March

Howe, C and White, S (1999) 'Integrated resource planning for water and waste water: Sydney case studies', Water International, Vol 24, No 4. 356-362.

Institute for Sustainable Futures (1998) Towards a Sustainable Water Future: the Sydney Water Least Cost Planning Study, research report prepared for Sydney Water Corporation, November.

Lovins, A B (1977) Soft Energy Paths: Towards a Durable Peace Pelican Books

Robinson, J B (1982) 'Energy Backcasting: a proposed method of policy analysis' Energy Policy 10 (4) 337-344

Rotmans, J, Asselt, M v, Anastasi, C, Greeuw, S, Mellors, J, Peters, S, Rothman, D and Rijkens, N (2000) 'Visions for a sustainable Europe' Futures 32 809-831

Turner, A, Campbell, S, White, S (2003) 'End use modeling and water efficiency programs for arid zones: the Alice Springs experience', Proceedings of Efficient 2003, The Second International Water Association Conference on Water Efficiency, Tenerife, Spain, April.

White, S. (1994) The Efficiency of Water Use - A Preliminary Assessment of Options for Improving Water Efficiency in the Sydney Region, research report prepared for the Sydney Water Project, Nature Conservation Council, September.

\section{Acknowledgements}

The Sydney Water End Use Model was commissioned in 1997 by Sydney Water Corporation as part of the Sydney Water Least Cost Planning Study, and the authors are grateful to Carol Howe, Doug Cox, Alan Gregory and the Sydney Water team for ongoing collaboration. Chris Riedy's research is sponsored by an Australian Postgraduate Award (Industrial) supported by the Australian Conservation Foundation.

\footnotetext{
${ }^{1}$ http://www.sydneywater.com.au

2 http://www.ipart.nsw.gov.au

${ }^{3}$ In Australia, these could be rated A, AA, AAA as described in http://ratings.wsaa.asn.au/
} 